\title{
Transcranial Stimulation of the Dorsolateral Prefrontal Cortex Prevents Stress-Induced Working Memory Deficits
}

\author{
Mario Bogdanov and Lars Schwabe \\ Department of Cognitive Psychology, Institute for Psychology, University of Hamburg, 20146 Hamburg, Germany
}

\begin{abstract}
Stress is known to impair working memory performance. This disruptive effect of stress on working memory has been linked to a decrease in the activity of the dorsolateral prefrontal cortex (dlPFC). In the present experiment, we tested whether transcranial direct current stimulation (tDCS) of the dIPFC can prevent stress-induced working memory impairments. We tested 120 healthy participants in a $2 \mathrm{~d}$, sham-controlled, double-blind between-subjects design. Participants completed a test of their individual baseline working memory capacity on day 1. On day 2, participants were exposed to either a stressor or a control manipulation before they performed a visuospatial and a verbal working memory task. While participants completed the tasks, anodal, cathodal, or sham tDCS was applied over the right dIPFC. Stress impaired working memory performance in both tasks, albeit to a lesser extent in the verbal compared with the visuospatial working memory task. This stress-induced working memory impairment was prevented by anodal, but not sham or cathodal, stimulation of the dIPFC. Compared with sham or cathodal stimulation, anodal tDCS led to significantly better working memory performance in both tasks after stress. Our findings indicate a causal role of the dIPFC in working memory impairments after acute stress and point to anodal tDCS as a promising tool to reduce cognitive deficits related to working memory in stress-related mental disorders, such as depression, schizophrenia, or post-traumatic stress disorder.
\end{abstract}

Key words: brain stimulation; dorsolateral prefrontal cortex; glucocorticoids; stress; working memory

Significance Statement

Working memory deficits are prominent in stress-related mental disorders, such as depression, schizophrenia, or post-traumatic stress disorder. Similar working memory impairments have been observed in healthy individuals exposed to acute stress. So far, attempts to prevent such stress-induced working memory deficits focused mainly on pharmacological interventions. Here, we tested the idea that transcranial direct current stimulation of the dorsolateral prefrontal cortex (dlPFC), a critical neural substrate of working memory, may prevent working memory impairments after stress. Our results indicate that anodal stimulation of the dIPFC may indeed preserve working memory performance under stress, suggesting that the dIPFC plays a causal role in stress-induced working memory deficits and pointing to a potential new avenue to prevent stress-induced cognitive impairments.

\section{Introduction}

Stress and major stress mediators, such as glucocorticoids and catecholamines, are well known to modulate a broad range of cognitive processes, ranging from attention and cognitive control to social cognition, decision-making, learning, and memory (Diamond et al., 2007; Lupien et al., 2007; Lupien et al., 2009; Roozendaal et al., 2009; Schwabe et al., 2012; Schwabe and Wolf,

\footnotetext{
Received Oct. 7, 2015; revised Dec. 9, 2015; accepted Dec. 19, 2015.

Author contributions: L.S. designed research;M.B. performed research;M.B. and L.S. analyzed data; M.B. and L.S. wrote the paper.

This work was supported by the University of Hamburg. We thank Dominika Kreft, Isatou Darbo, Livia Wilheim, and Alicia Weisener for assistance during data collection.

The authors declare no competing financial interests.

Correspondence should be addressed to Dr. Lars Schwabe, University of Hamburg, Department of Cognitive Psychology, 20146 Hamburg, Germany, E-mail: Lars.Schwabe@uni-hamburg.de.

DOI:10.1523/JNEUROSCI.3687-15.2016

Copyright $\odot 2016$ the authors $\quad 0270-6474 / 16 / 361429-09 \$ 15.00 / 0$
}

2013; Sandi and Haller, 2015). Specifically, working memory processes are among those cognitive functions that are most sensitive to the effects of stress and stress hormones, with most studies reporting impaired working memory after stress (Diamond et al., 1999; Lupien et al., 1999; Roozendaal et al., 2004; Elzinga and Roelofs, 2005; Schoofs et al., 2009). Given that working memory deficits are also prominent in stress-related psychopathology (Goldman-Rakic, 1994; Snyder, 2013; Honzel et al., 2014), it is important to find reliable methods to reduce or prevent stressinduced working memory impairments.

Working memory processes are subserved by a large network of interconnected cortical and subcortical brain regions (GoldmanRakic, 1987; Fuster, 1997; Rottschy et al., 2012; Sreenivasan et al., 2014), with the dorsolateral prefrontal cortex (dlPFC) playing a critical role in this network (Fuster and Alexander, 1971; Jonides et al., 1993; D’Esposito et al., 1995; McCarthy et al., 1996; Barbey et al., 2013). As the dlPFC is one of the most stress-sensitive brain areas (de 
Kloet et al., 2005; McEwen and Morrison, 2013), it is thought that neurotransmitters and hormones that are released in response to stressful encounters downregulate dlPFC activity and thus impede working memory performance. Previous studies using fMRI confirmed that acute stress reduces working memory-related activity in the dlPFC (Qin et al., 2009). Moreover, pharmacological alterations of catecholamine levels, specifically dopamine and noradrenaline levels, in the dlPFC were shown to impair working memory performance in rodents (Brozoski et al., 1979; Arnsten and GoldmanRakic, 1985; Arnsten and Li, 2005; Arnsten, 2009). Based on these findings, attempts have been made to counteract stress-induced working memory impairments by pharmacologically blocking the action of stress mediators (Conrad et al., 1996; Murphy et al., 1996; Martin and Wellman, 2011). Although such pharmacological manipulations may be successful, drugs can have serious side effects, and identifying techniques to prevent stress-induced working memory deficits that can be used safely in humans is crucial.

Transcranial direct current stimulation (tDCS) is a safe, noninvasive technique to stimulate specific brain areas with low electric current that is delivered via anode and cathode electrodes (Nitsche and Paulus, 2000; Nitsche et al., 2008). Combinations of neuroimaging and tDCS demonstrated that anodal tDCS increases task-related dlPFC activation (Stagg et al., 2013; Weber et al., 2014). Moreover, anodal tDCS over the dlPFC has been shown to facilitate working memory processes (Fregni et al., 2005; Boggio et al., 2006; Nitsche et al., 2008), making tDCS a promising tool for the amelioration of stress-induced working memory impairments. Therefore, the aim of this study was to investigate whether anodal tDCS can be used to counteract working memory deficits after stress. To this end, we first determined the individual baseline working memory capacity using standardized working memory tasks that are often used in clinical settings (Corsi block backwards and digit span backwards). On the next day, we assessed the effect of stress on working memory: participants underwent the Trier Social Stress Test (TSST) (Kirschbaum et al., 1993) or a control manipulation before completing the two working memory tasks. Critically, while participants performed the tasks, anodal, cathodal, or sham tDCS was applied over the right dlPFC. We chose to stimulate the right dlPFC because neuroimaging data indicated that acute stress decreases working memory-related activity in the right dlPFC (Qin et al., 2009). We hypothesized that anodal, but not sham, dlPFC stimulation would reduce stress-induced working memory impairments. As cathodal tDCS is assumed to decrease neural excitability (Nitsche and Paulus, 2000), we speculated that cathodal tDCS might even potentiate the impairing effect of stress on working memory.

\section{Materials and Methods}

Participants and experimental design. A total of 120 healthy, normalweight volunteers between 18 and 32 years of age participated in this experiment ( 60 females; age, mean \pm SEM: $25.2 \pm 0.31$ years; body mass index, $22.44 \pm 0.24 \mathrm{~kg} / \mathrm{m}^{2}$ ). Participants did not have any current or acute illnesses or a lifetime history of any psychiatric or neurological disorder. In addition, exclusion criteria included medication intake, smoking, drug abuse, any contraindications for tDCS, and pregnancy or use of hormonal contraceptives in women. Women were not tested during their menses. Further, participants were asked to refrain from physical exercise, food and caffeine intake within the $2 \mathrm{~h}$ before testing. All participants provided written informed consent before the experiment and received a monetary compensation of 25 euros at the end of testing. The study protocol was approved by the ethics committee of the German Psychological Association.

We used a double-blind, sham-controlled, fully crossed, betweensubject design with the factors stress condition (TSST vs control manipulation) and tDCS condition (anodal vs cathodal vs sham tDCS), resulting in six experimental groups to which participants were randomly assigned (10 men and 10 women per group). For the digit span backwards task, eight participants (one or two participants of each experimental group) appeared to have difficulties understanding the task and were classified as outliers based on canonical statistical criteria (i.e., $>2$ SD below the group average; Tabachnick and Fidell, 2005), thus leaving a sample of 112 participants for the digit span task analyses.

Experimental stress induction. In the stress condition, participants were exposed to the TSST (Kirschbaum et al., 1993), a standardized paradigm in experimental stress research that is known to lead to substantial increases of subjective stress levels, sympathetic activity, and cortisol concentrations (Kirschbaum et al., 1993; Dickerson and Kemeny, 2004; Smeets et al., 2012). In the TSST, participants underwent a mock job interview, comprising a free speech about why they are the ideal candidate for the job and a rather difficult mental arithmetic task, each lasting $5 \mathrm{~min}$, in front of a panel of two rather cold, nonreinforcing experimenters (1 male, 1 female). Furthermore, participants were videotaped during the TSST. In the control condition, participants gave a 5 min speech about a topic of their choice (e.g., last holiday) and performed a simple arithmetic task for $5 \mathrm{~min}$ while being alone in the experimental room; no video recordings were taken. During the control condition, the experimenter waited in front of the door outside the room where he/she was able to hear whether the participants complied with the instructions. In retrospect, all participants in the control condition complied with the instructions.

To evaluate the successful stress induction, subjective and physiological measurements were taken at several time points across the experiment. More specifically, participants completed a German mood scale (Multidimensional Mood Questionnaire; Eid et al., 1994) that assesses subjective feelings on three bipolar dimensions (elevated vs depressed mood, wakefulness vs sleepiness, calmness vs restlessness; higher scores indicating more depressed mood, higher sleepiness, and higher restlessness) and rated the stressfulness, difficulty, and unpleasantness of the previous experience immediately after the TSST or control manipulation on a scale form 0 ("not at all") to 100 ("very much"). In addition, blood pressure and pulse were measured using a Dinamap system (Critikon) before, during, immediately after the TSST/control manipulation, and before and after the working memory tasks. To quantify cortisol concentrations and elevations during the experiment, saliva samples were collected from participants using Salivette collection devices (Sarstedt) at several time points before and after the TSST/control manipulation. Saliva samples were stored at $-18^{\circ} \mathrm{C}$ and subsequently analyzed for cortisol concentrations using a luminescence assay (IBL).

tDCS. tDCS was applied in a double-blind, sham-controlled manner using a Neuroconn stimulator. In line with previous tDCS studies that focused on the dIPFC (Harty et al., 2014; Zwissler et al., 2014; Axelrod et al., 2015; Pope et al., 2015), we used an EEG cap and the standard 10-20 system to determine electrode positions individually for each participant. The smaller electrode $(5 \times 5 \mathrm{~cm})$ was positioned over the right dlPFC (position F4). The larger electrode $(10 \times 10 \mathrm{~cm})$, which served as a reference (Nitsche and Paulus, 2000), was fixed centrally on the head (position CZ). Different electrode sizes were chosen so that a higher, functionally effective current density was applied over the dlPFC (the area of interest) than over central regions underlying the functionally ineffective, large electrode. Both electrodes were covered in sponges soaked with a sodium chloride solution to improve conductivity and to reduce skin irritation. Based on recent findings suggesting that tDCS of 1 $\mathrm{mA}$ may be most efficient (Hoy et al., 2013), we applied a current of 1.075 $\mathrm{mA}$ for active stimulation. Given the different electrode sizes of 25 and $100 \mathrm{~cm}^{2}$, respectively, this leads to a current density of $0.043 \mathrm{~mA} / \mathrm{cm}^{2}$ for the electrode over the dlPFC and $0.011 \mathrm{~mA} / \mathrm{cm}^{2}$ for the reference electrode, making it much less likely for the larger electrode to induce functional effects on the underlying brain tissue. The electrode setup was identical in all conditions. In the anodal condition, the electrode over the dlPFC served as the anode, whereas the reference electrode served as the cathode. In the cathodal condition, the polarity of the electrodes was reversed. Active brain stimulation was stopped once the participant had finished the working memory task. In all conditions, the current was applied with an $8 \mathrm{~s}$ fade-in and a $5 \mathrm{~s}$ fade-out-window at the beginning 
Table 1. Subjective and physiological data on day $1^{a}$

\begin{tabular}{|c|c|c|c|c|c|c|c|}
\hline & \multicolumn{3}{|l|}{ MDBF } & \multicolumn{2}{|l|}{ Blood pressure } & \multirow[b]{2}{*}{ Pulse } & \multirow[b]{2}{*}{ Salivary cortisol } \\
\hline & Elevated mood & Wakefulness & Calmness & Systolic & Diastolic & & \\
\hline \multicolumn{8}{|l|}{ Stress condition } \\
\hline Sham group & $32.75 \pm 1.05$ & $26.50 \pm 1.03$ & $31.85 \pm 1.12$ & $134.60 \pm 3.62$ & $76.70 \pm 1.80$ & $74.85 \pm 2.23$ & $5.75 \pm 0.92$ \\
\hline \multicolumn{8}{|l|}{ Control condition } \\
\hline Anodal group & $32.90 \pm 1.05$ & $26.60 \pm 1.22$ & $30.85 \pm 0.86$ & $137.68 \pm 4.04$ & $79.30 \pm 2.44$ & $76.50 \pm 2.94$ & $7.69 \pm 1.50$ \\
\hline
\end{tabular}

${ }^{a}$ Data are mean \pm SEM. MDBF, Multidimensional Mood Questionnaire. Systolic and diastolic blood pressure is given in $\mathrm{mmHg}$, pulse in beats-per-minute (bpm), and salivary cortisol in nmol/l.

and the end of the stimulation, respectively. In the sham condition, the initial fade-in-period was immediately followed by the fade-out-period. Thereafter no current was delivered in the sham condition. This setup prevented participants from explicitly understanding to which condition they had been assigned. Investigator and participant were oblivious to the condition applied, through the use of preprogrammed codes of the Neuroconn stimulator.

Working memory tasks. Working memory was assessed using two standardized tasks that are frequently used to assess working memory capacity in clinical settings: the Corsi block backward task assessing visuospatial working memory and the digit span backward assessing verbal working memory (Wechsler, 1997, 2008). In the Corsi block backwards task, the experimenter tapped on a number of squares, one after the other, on a sheet of paper lying in front of the participants. Participants were asked to memorize the sequence and to subsequently reproduce it in reversed order. The experimenter started with a sequence consisting of three squares and extended the sequence by one square every second trial. The task was stopped when participants were not able to reproduce at least one sequence for a given span correctly. In the digit span backwards task, the experimenter read a sequence of one-digit numbers aloud and participants were required to reproduce the digits in reversed order. The digit span task started with a sequence of four onedigit numbers and the digit span was increased by one digit every second trial. The task was stopped when participants were not able to reproduce at least one of the two presented spans correctly. In both tasks, one point was given for each correctly reproduced trial, and overall task performance was expressed as the score reached (Busch et al., 2005; Kessels et al., 2008; Wechsler, 2008). We chose to administer backward versions of both working memory tasks because our sample consisted of healthy university students and the forward versions would have been most likely to easy for this sample, leading to ceiling effects. Because participants completed each task on both experimental days, we used parallel versions to avoid potential carryover effects.

Procedure. Participants were tested between 1:00 P.M. and 6:00 P.M. on two consecutive days. On day 1, participants completed the Trier Inventory for the Assessment of Chronic Stress (Schulz and Schlotz, 1999) before ratings of subjective feeling, blood pressure, and pulse measurements and a saliva sample were taken, to control for potential group differences in the stress level before the baseline measurement of working memory performance. Participants then completed the Corsi block backward and digit span backward tasks, with task order being counterbalanced across participants. The working memory tests on day 1 served to familiarize participants with the tasks and to provide a "baseline" measurement of the individual working memory capacity.

On day 2, participants completed the Beck Depression Inventory (Beck et al., 1996) to control for interfering influences of depressive symptoms. Subsequently, baseline measurements of subjective and physiological stress parameters were taken (i.e., Multidimensional Mood Questionnaire, blood pressure, pulse, and cortisol). Depending on the experimental condition, participants then performed the TSST or the control manipulation. After the TSST or control manipulation, subjective and physiological stress measurements were taken again and electrodes were applied to the head for tDCS. Twenty minutes after the TSST/control manipulation, subjective and physiological stress levels were measured again before tDCS was applied. Shortly after the begin- ning of anodal, cathodal, or sham dlPFC stimulation, participants completed the Corsi block backwards and the digit span backwards tasks (task order counterbalanced across participants; different items than on day 1). Task instructions were given to the participants after the initial $8 \mathrm{~s}$ fade-in period to allow for maximum stimulation intensity during the tasks; behavioral testing started $\sim 15-20 \mathrm{~s}$ after the fade-in period. The interval of $\sim 30$ min between stressor onset and start of testing was chosen because stress-induced cortisol elevations were expected to peak at that time (Kirschbaum et al., 1993). All participants completed the tasks within 6-10 $\mathrm{min}$ (average duration: $\sim 8 \mathrm{~min}$ ), thus resulting also in a stimulation duration of 6-10 min. After participants had finished both tasks, brain stimulation was stopped and electrodes were removed. At the end of the experiment, subjective and physiological measures were taken again. Participants were asked to guess what type of tDCS they had received and were then debriefed.

Data analysis. Subjective and physiological parameters were analyzed using a mixed-design ANOVA with time point of measurement as within-subject factor and stress condition (stress vs control) and tDCS condition (anodal vs cathodal vs sham) as between-subject factors.

The critical behavioral parameter was the change in working memory performance from day 1 to day 2 because this change takes differences in individual working memory capacities into account and allows the assessment of working memory changes due to stress and dlPFC stimulation, respectively, independent of the individual "baseline" working memory capacity. This difference score was subjected to an ANOVA with stress condition (stress vs control), tDCS condition (anodal vs cathodal vs sham), and sex (female vs male) as between-subject-factors. Participants' sex was included as an additional factor because previous evidence suggested that stress effects on memory processes may differ in men and women (Cahill, 2006; Andreano and Cahill, 2009; Guenzel et al., 2014). Significant main or interaction effects were further pursued by appropriate post hoc tests that were corrected for multiple comparisons, if required. Critical $p$ values were set to $p<0.05$. All reported $p$ values are two-tailed.

\section{Results}

\section{Indicators of successful stress induction}

There were no group differences in subjective and physiological parameters on day 1 , indicating that groups did not differ in their stress level before baseline working memory testing (all $p>0.30$; Table 1).

Subjective and physiological data on day 2 verified the successful stress induction by the TSST. Although groups did not differ in their subjective ratings before the TSST/control manipulation (all $p>0.13$; Table 2 ), participants who were exposed to the TSST reported lower mood and calmness compared with participants in the control group after the experimental manipulation (time $\times$ stress condition interaction effects for mood and calmness: both $F>14.40$, both $p<0.001$; Bonferroni-corrected post hoc tests: both $p<0.001$ ); participants' wakefulness ratings remained unaffected by the TSST (time $\times$ stress condition interaction: $\left.F_{(2.72,307.62)}=1.16, p=0.32\right)$. Moreover, participants who underwent the TSST experienced the stress condition as signifi- 
Table 2. Subjective stress ratings on day $2^{a}$

\begin{tabular}{|c|c|c|c|c|}
\hline & \multicolumn{2}{|c|}{ Stress condition } & \multicolumn{2}{|c|}{ Control condition } \\
\hline & Mean & SEM & Mean & SEM \\
\hline \multicolumn{5}{|l|}{ Elevated versus depressed mood (MDBF) } \\
\hline Before TSST/control manipulation & 33.58 & 0.57 & 32.55 & 0 \\
\hline After TSST/control manipulation & $28.12^{* * * *}$ & 0.96 & 32.78 & \\
\hline Before working memory testing & $29.32^{* *}$ & 0.90 & $30.70^{* *}$ & 0 \\
\hline After working memory testing & $31.30^{* *}$ & 0.79 & 31.98 & 0 \\
\hline \multicolumn{5}{|l|}{ Calmness versus restlessness (MDBF) } \\
\hline Before TSST/control manipulation & 32.20 & 0.61 & 30.65 & 0. \\
\hline After TSST/control manipulation & $24.47^{*, * *}$ & 0.94 & 30.65 & 0 \\
\hline Before working memory testing & $27.71^{* *}$ & 0.89 & $29.05^{* *}$ & 0. \\
\hline After working memory testing & $30.47^{* *}$ & 0.82 & 30.72 & 0. \\
\hline \multicolumn{5}{|l|}{ Wakefulness versus sleepiness (MDBF) } \\
\hline Before TSST/control manipulation & 28.00 & 0.63 & 27.17 & 0.7 \\
\hline After TSST/control manipulation & 28.03 & 0.52 & 26.47 & 0 \\
\hline Before working memory testing & 28.10 & 0.56 & 27.05 & 0 \\
\hline After working memory testing & 27.38 & 0.62 & $25.57^{* *}$ & 0. \\
\hline \multicolumn{5}{|l|}{$\begin{array}{l}\text { Subjective rating of the TSST/control } \\
\text { manipulation }\end{array}$} \\
\hline Stressfulness & $65.17^{*}$ & 3.49 & 33.33 & \\
\hline Difficulty & $72.50^{*}$ & 2.75 & 29.33 & 3 \\
\hline Unpleasantness & $67.67^{*}$ & 3.72 & 28.33 & 3. \\
\hline
\end{tabular}

${ }^{a}$ MDBF, Multidimensional Mood Questionnaire.

*Significant difference between stress and control condition $(p<0.001)$.

**Within-group differences compared with the baseline measurement $(p<0.05)$.

cantly more stressful, difficult, and unpleasant than participants who underwent the control manipulation (all $t_{(118)}>7$, all $p<$ $0.001)$. On the physiological level, exposure to the TSST led to significant increases in participants' pulse (time $\times$ stress condition interaction: $\left.F_{(2.33,251.88)}=84.00, p<0.001\right)$, diastolic blood pressure $\left(F_{(3.49,361.84)}=36.92, p<0.001\right)$ and systolic blood pressure $\left(F_{(3.11,345.31)}=19.09, p<0.001\right)$. As shown in Figure $1 A-C$, groups did not differ in their pulse and blood pressure before the TSST/control manipulation, yet participants who were exposed to the TSST had higher blood pressure and pulse during and shortly after the manipulation. Finally, the TSST caused also the expected rise in salivary cortisol; although the TSST and control groups did not differ in their baseline cortisol concentrations $\left(t_{(118)}=0.31, p=0.76\right)$, cortisol increased after the TSST but not after the control manipulation (time $\times$ stress condition interaction: $F_{(2.11,238.11)}=25.01, p<0.001$; Fig. 2). Salivary cortisol concentrations were elevated in the TSST group, compared with the control group, at each time point of measurement after the TSST (all $p \leq 0.001$ ) and reached their maximum $\sim 30$ min after stressor onset, shortly before working memory testing started.

Critically, there were no differences between the tDCS groups in any of the subjective or physiological responses to the TSST (time $\times$ stress condition $\times$ tDCS condition interactions: all $F<$ 1.52 , all $p>0.17)$.

\section{Anodal stimulation of the dlPFC abolishes stress-induced working memory impairments}

Groups did not differ in their working memory performance on day 1 (Corsi block backwards: $F_{(2,108)}=0.72, p=0.49$; digit span backwards: $F_{(2,100)}=1.38, p=0.26$; Table 3$)$. Yet, as expected, there were considerable differences in working memory capacity between individual participants (range: $2-11$ [Corsi span]; 1-12 [digit span]). To take these individual differences in working memory capacities into account and assess the impact of stress and/or tDCS on working memory independent of such baseline differences, performance on day 2 was expressed as $\Delta$ score relative to day 1 performance.

For the Corsi block task, we obtained a significant main effect of stress condition $\left(F_{(1,108)}=7.13, p=0.009\right)$ and a trend for a main effect of tDCS condition $\left(F_{(2,108)}=3.01, p=0.054\right)$. Most importantly, however, we found a significant interaction between stress condition and tDCS condition $\left(F_{(2,108)}=3.36, p=0.039\right)$. Participants who underwent the TSST performed significantly better when they received anodal dlPFC stimulation than when they received sham $(p<0.01)$ or cathodal stimulation $(p<0.05$; main effect tDCS condition in the stress condition: $F_{(2,60)}=5.92$, $p=0.005)$; in the control condition, there was no effect of tDCS condition $\left(F_{(2,60)}=0.24, p=0.98\right)$. As shown in Figure $3 A$, the exposure to the TSST resulted in a decline in Corsi block performance in the sham condition (main effect stress condition: $\left.F_{(1,36)}=9.80, p=0.003\right)$ and a trend toward impaired performance in the cathodal condition $\left(F_{(1,36)}=3.92, p=0.055\right)$. Under anodal dlPFC stimulation, however, TSST exposure did not decrease Corsi block performance $\left(F_{(1,36)}=0.15, p=0.70\right)$. Overall, men outperformed women in the Corsi block task $\left(F_{(1,108)}=5.31, p=0.02\right)$, yet the influence of stress and tDCS condition did not differ in men and women (stress condition $X$ tDCS condition $\times$ sex: $\left.F_{(2,108)}=2.08, p=0.13\right)$.

The pattern of results in the digit span backwards task was very similar to that observed in the Corsi block task. In addition to a main effect of tDCS condition $\left(F_{(2,100)}=5.02, p=0.008\right)$, we obtained a marginally significant interaction of stress condition and tDCS condition $\left(F_{(2,100)}=2.96, p=0.057\right)$. Importantly, after stress, participants in the anodal tDCS condition performed significantly better than those in the sham $(p=0.002)$ or in the cathodal condition ( $p=0.003$; main effect of tDCS condition in the stress condition: $\left.F_{(2,55)}=7.05, p=0.002\right)$, whereas there was no effect of tDCS condition after the control manipulation $\left(F_{(2,54)}=0.52, p=0.60\right)$. As displayed in Figure $3 B$, stress tended to decrease working memory performance in the sham group $\left(F_{(1,35)}=3.26, p=0.08\right)$ and in the cathodal group $\left(F_{(1,35)}=\right.$ $2.27, p=0.12)$ but not in the anodal group $\left(F_{(1,36)}=1.27, p=\right.$ $0.23)$. There was no main or interaction effect including the factor sex (all $p>0.26)$. For both tasks, performance on day 2 was (in the control condition) better than performance on day 1, which was most likely due to practice and familiarity effects.

Although the cortisol response to the stressor did not differ between the tDCS groups (see above), we wanted to make sure that the facilitating effects of anodal tDCS were not related to differences in cortisol responses; we performed an additional analysis in which we included the peak cortisol level (before working memory testing) as a covariate. There was, however, no main effect for this covariate in either task (both $F<1.90$; both $p>0.17)$; and, importantly, the stress condition $\times$ tDCS condition interactions remained as described above, indicating that differential cortisol levels before testing cannot explain the impact of anodal tDCS.

\section{Control variables}

There were no group differences in chronic stress level or depressive symptoms (all $F<1.90$, all $p>0.15$; Table 4 ), indicating that these factors could not explain our results.

When participants were asked to guess whether they had received active or sham tDCS, most participants (67\%) assumed that they had received active stimulation, regardless of the actual tDCS condition. Participants were not able to discriminate between the different stimulation types $\left(\chi_{2}^{2}=3.57, p=0.17\right)$. Moreover, there were no side effects of stimulation. 

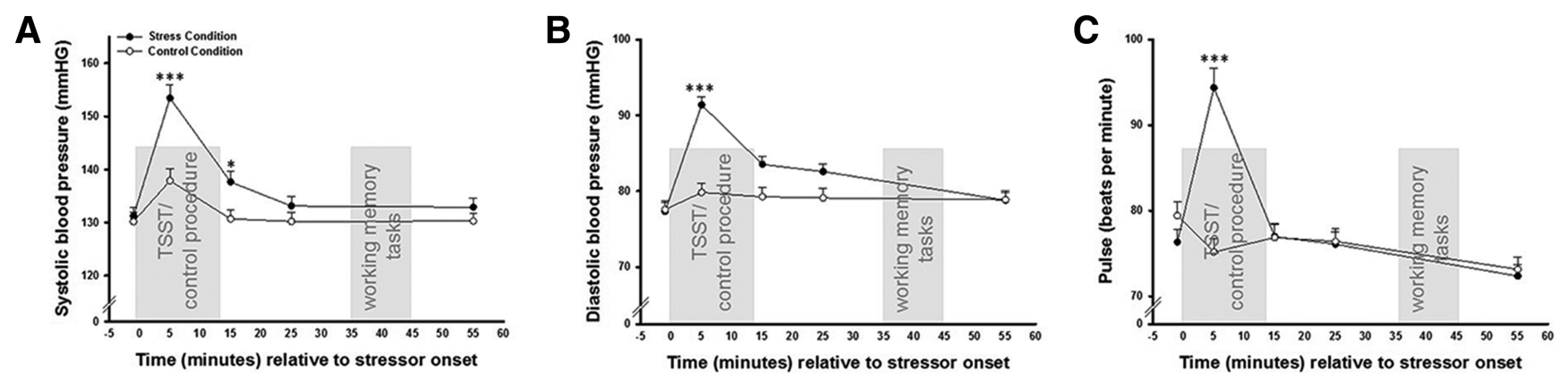

Figure 1. Sympathetic nervous system responses to the TSST. Exposure to the TSST, but not to the control manipulation, led to significant increases in systolic blood pressure ( $\boldsymbol{A})$, diastolic blood pressure $(\boldsymbol{B})$, and pulse ( $\boldsymbol{C}$. Stress and control groups differed in these parameters during the TSST/control manipulation and shortly thereafter but not before the TSST/control manipulation or before working memory testing started. Error bars indicate SEM. ${ }^{*} p<0.05{ }^{* * *} p<0.001$.

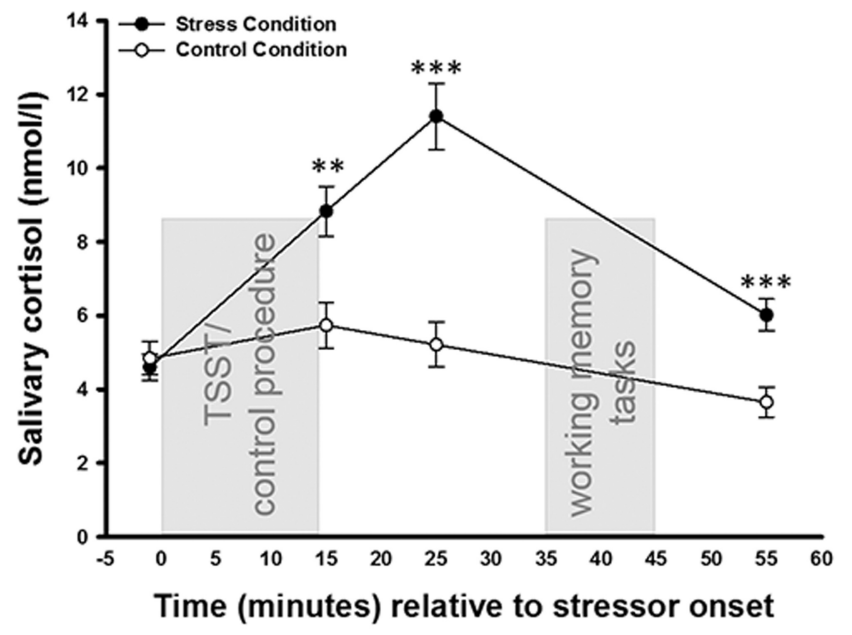

Figure 2. Salivary cortisol responses to the TSST. Cortisol concentrations increased in response to the TSST but not in response to the control manipulation. Peak cortisol concentrations were reached shortly before working memory testing started. Error bars indicate SEM. ${ }^{* *} p<0.01$. ${ }^{* *} p<0.001$.

Table 3. Performance in working memory tasks on day $1^{a}$

\begin{tabular}{lll}
\hline & Corsi block backwards & Digit span backwards \\
\hline $\begin{array}{l}\text { Stress condition } \\
\text { Anodal group }\end{array}$ & $6.35 \pm 0.36$ & \\
$\quad$ Cathodal group & $6.50 \pm 0.46$ & $3.90 \pm 0.58$ \\
$\quad$ Sham group & $7.05 \pm 0.43$ & $4.50 \pm 0.50$ \\
Control condition & & $4.05 \pm 0.61$ \\
$\quad$ Anodal group & $6.05 \pm 0.46$ & \\
$\quad$ Cathodal group & $6.25 \pm 0.41$ & $4.25 \pm 0.44$ \\
$\quad$ Sham group & $5.90 \pm 0.37$ & $4.25 \pm 0.66$ \\
\hline a & & $3.10 \pm 0.44$ \\
\hline
\end{tabular}

\section{Discussion}

Working memory deficits are a characteristic feature of stressrelated disorders, such as major depression, schizophrenia, or post-traumatic stress disorder (Goldman-Rakic, 1994; Snyder, 2013; Honzel et al., 2014). Here, we tested whether transcranial stimulation of the dlPFC, the key locus of working memory in the brain (Fuster and Alexander, 1971; D'Esposito et al., 1995; D'Esposito et al., 1998), could prevent the disruptive influence of acute stress on working memory performance. The present findings show that dlPFC stimulation with anodal tDCS may indeed prevent stress-induced working memory impairments. Compared with cathodal and sham stimulation, anodal dlPFC stimulation led to significantly better performance after stress, in two separate working memory tasks. Because we controlled for "baseline" differences in working memory, these effects cannot be attributed to individual differences in working memory capacity.

Corroborating earlier studies, we show that acute stress disrupts working memory performance (Diamond et al., 1999; Lupien et al., 1999; Schoofs et al., 2009), although this effect appeared to be stronger for visual spatial working memory (Corsi span) than for verbal working memory (digit span). Most importantly, however, our findings suggest a critical role of the dlPFC in this stress-induced working memory impairment. This finding is in line with fMRI evidence showing a stress-related decrease in dlPFC activity during a working memory task (Qin et al., 2009). However, fMRI data are correlational, not causal; and, in addition to brain lesions, only brain stimulation techniques, such as tDCS, allow conclusions about causal relationships between brain and behavior. Although we propose a causal role of the dlPFC in working memory deficits after stress, other brain areas also need to be taken into account. It is well established that complex cognitive functions, such as working memory, rely on a network of interconnected brain areas (Smith and Jonides, 1997; Pessoa, 2008). More specifically, it was shown in rats that working memory deficits after stress hormone administration are mediated by the basolateral amygdala interacting with the medial PFC (Roozendaal et al., 2004). Altered medial PFC activity has been directly linked to impaired working memory after glucocorticoid administration (Barsegyan et al., 2010). Medial and dorsolateral prefrontal areas are thought to belong to functionally distinct networks (Fox et al., 2005; Gerlach et al., 2011), and their activity is often negatively correlated (Baumgartner et al., 2011; Haller and Schwabe, 2014). Hence, we suggest that stress results in altered crosstalk of limbic and prefrontal areas that ultimately leads to reduced dlPFC activation and impaired working memory. Anodal stimulation of the dlPFC targeted this "endpoint" and could thus abolish the stress-induced working memory impairment.

However, how exactly may anodal tDCS have prevented the impairing effect of stress on working memory? Rapid effects of acute stress on working memory are thought to be mediated by glucocorticoids, in concert with catecholamines, acting via membrane-bound glucocorticoid receptors (Barsegyan et al., 2010). Activation of membrane-bound glucocorticoid receptors decreases synaptic and neuronal excitability by reducing calcium currents through NMDA receptors and voltage-gated calcium channels via protein kinase A and G-protein-dependent mechanisms (Prager and Johnson, 2009). In contrast to these stress hormone effects, anodal tDCS increases neuronal excitability. These excitability increases are eliminated by a sodium channel blocker as well as by a calcium channel blocker (Liebetanz et al., 

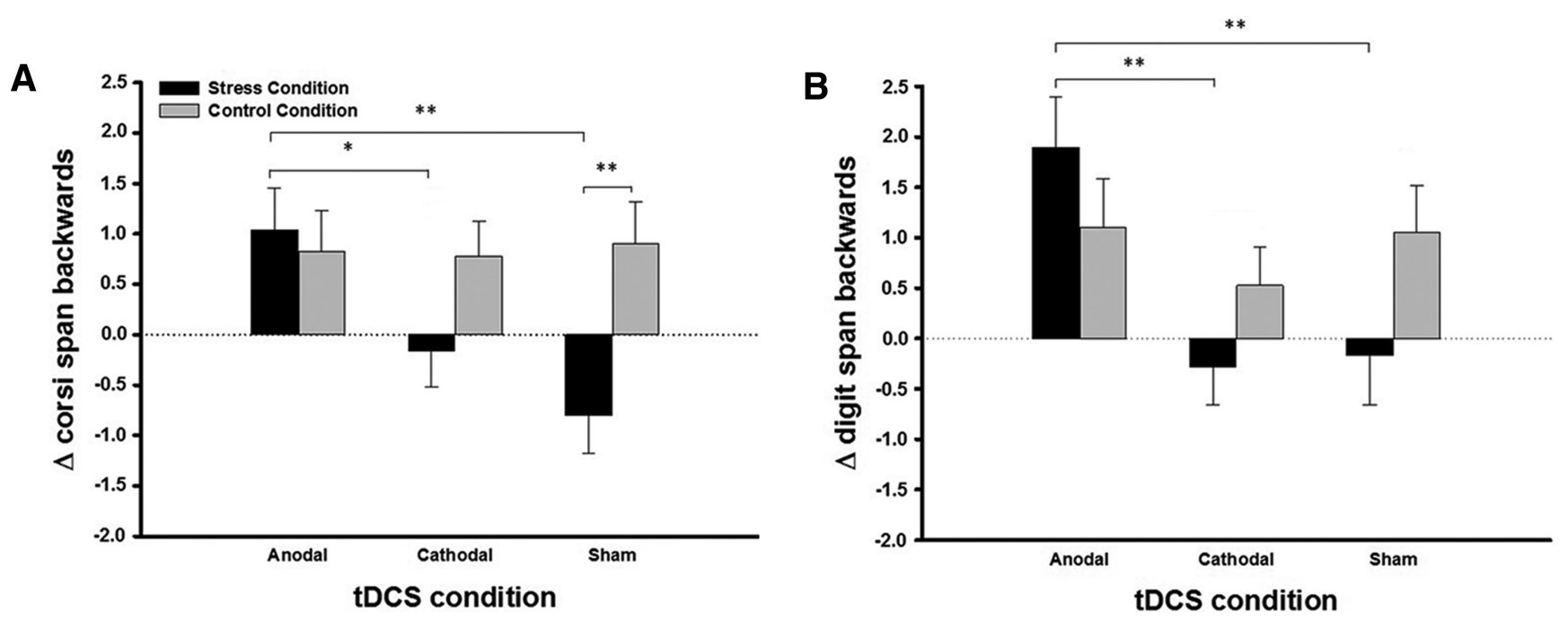

Figure 3. Anodal tDCS prevents stress-induced working memory impairments. $\boldsymbol{A}$, Exposure to the TSST impaired Corsi block backwards performance, an indicator of visual-spatial working memory, in the sham and cathodal tDCS groups but not in the anodal tDCS group. $\boldsymbol{B}$, Similarly, TSST exposure tended to reduce digit span backwards performance, an indicator of verbal working memory, in the sham and cathodal tDCS groups but not in the anodal tDCS group. In both tasks, working performance after stress was significantly better in participants that received anodal tDCS over the dIPFC than in those that received sham or cathodal stimulation. Error bars indicate SEM. ${ }^{*} p<0.05 .{ }^{* *} p<0.01$.

Table 4. Depression and chronic stress scores ${ }^{a}$

\begin{tabular}{|c|c|c|c|c|c|c|}
\hline & \multicolumn{3}{|l|}{ Stress } & \multicolumn{3}{|l|}{ Control } \\
\hline & Anodal & Cathodal & Sham & Anodal & Cathodal & Sham \\
\hline BDI & $8.90 \pm 1.55$ & $6.55 \pm 1.03$ & $6.15 \pm 1.21$ & $6.25 \pm 1.00$ & $7.85 \pm 1.89$ & $8.45 \pm 1.16$ \\
\hline \multicolumn{7}{|l|}{ TICS scales } \\
\hline Work overload & $13.42 \pm 1.51$ & $13.75 \pm 1.44$ & $13.75 \pm 1.85$ & $13.75 \pm 1.72$ & $14.35 \pm 1.54$ & $12.10 \pm 1.30$ \\
\hline Social overload & $8.58 \pm 1.14$ & $8.16 \pm 0.91$ & $7.00 \pm 0.99$ & $6.70 \pm 0.98$ & $8.79 \pm 1.09$ & $7.33 \pm 0.89$ \\
\hline Performance pressure & $16.85 \pm 1.61$ & $14.75 \pm 1.58$ & $16.05 \pm 1.52$ & $16.04 \pm 1.57$ & $17.10 \pm 1.28$ & $16.25 \pm 1.17$ \\
\hline Work discontent & $14.90 \pm 0.80$ & $10.74 \pm 1.36$ & $13.40 \pm 1.50$ & $12.35 \pm 1.07$ & $12.35 \pm 1.35$ & $15.21 \pm 1.09$ \\
\hline Excessive workload & $8.37 \pm 0.71$ & $7.58 \pm 0.93$ & $6.85 \pm 1.18$ & $7.16 \pm 1.12$ & $6.44 \pm 0.90$ & $8.79 \pm 1.05$ \\
\hline Lack of social recognition & $5.58 \pm 0.60$ & $5.72 \pm 0.99$ & $5.50 \pm 0.80$ & $4.68 \pm 0.65$ & $4.37 \pm 0.56$ & $6.00 \pm 0.71$ \\
\hline Social tension & $9.80 \pm 0.95$ & $8.85 \pm 1.07$ & $9.79 \pm 1.18$ & $8.70 \pm 1.15$ & $9.47 \pm 1.09$ & $11.53 \pm 0.96$ \\
\hline Social isolation & $8.60 \pm 0.89$ & $7.56 \pm 0.95$ & $8.94 \pm 1.38$ & $7.68 \pm 1.02$ & $7.74 \pm 1.12$ & $9.95 \pm 1.02$ \\
\hline Chronic worrying & $8.37 \pm 0.88$ & $6.95 \pm 0.85$ & $6.70 \pm 0.92$ & $7.20 \pm 0.82$ & $6.50 \pm 0.89$ & $7.63 \pm 0.81$ \\
\hline TICS screening scale & $19.84 \pm 2.01$ & $18.05 \pm 2.04$ & $17.30 \pm 2.36$ & $17.25 \pm 2.11$ & $16.15 \pm 1.85$ & $17.85 \pm 1.87$ \\
\hline
\end{tabular}

${ }^{a}$ Data are mean \pm SEM. BDI, Beck Depression Inventory; TICS, Trier Inventory of Chronic Stress.

2002; Nitsche et al., 2003), suggesting that cortical excitability changes during tDCS require membrane polarization, mediated through sodium and calcium channels. Moreover, tDCS induces aftereffects in neuroplasticity that are mediated by NMDA receptors (Liebetanz et al., 2002; Nitsche et al., 2003). Based on these data, we propose that stimulation of the dlPFC using anodal tDCS prevented decreases in working memory performance after stress by counteracting stress-induced decreases in neuronal excitability.

Whereas anodal dlPFC stimulation improved working memory performance after stress, we obtained no effect of cathodal dlPFC stimulation. Although there is some physiological evidence for an inhibitory influence of cathodal tDCS (Nitsche and Paulus, 2000), a number of studies failed to find differences between cathodal and sham stimulation (e.g., Kincses et al., 2004; Marshall et al., 2005; Sparing et al., 2008), and it is argued that the effect of cathodal stimulation might be less reliable and more task-dependent than that of anodal stimulation (Jacobson et al., 2012). For anodal dlPFC stimulation, several studies reported enhancing effects on working memory performance (Fregni et al., 2005; Andrews et al., 2011; Zaehle et al., 2011). In the present experiment, however, we observed no working memory enhancement during anodal dlPFC stimulation in the control con- dition, which would have been expected based on previous studies showing working memory enhancements during and after tDCS over the dlPFC (Fregni et al., 2005; Andrews et al., 2011; Zaehle et al., 2011). This discrepancy with earlier reports might be due to stimulation parameters, such as the intensity, timing, and duration of stimulation or the chosen stimulation site. For example, we stimulated the right dlPFC because neuroimaging data showed a robust decrease in working memory-related activity in this area after stress (Qin et al., 2009). Previous studies that reported enhanced working memory during tDCS over the dlPFC, however, typically stimulated the left dlPFC (Fregni et al., 2005; Boggio et al., 2006).

Finally, it is important to note that working memory is a complex, high-level cognitive function, composed of different subprocesses (Baddeley, 2003; Nee et al., 2013) (e.g., attention, processing speed), and from our data we cannot conclude exactly which of these processes were modulated by tDCS. We used two tasks that are frequently used to assess working memory performance in both healthy and clinical individuals (Harvey et al., 2004; Castaneda et al., 2008). However, these tasks did not allow us to measure subprocesses of working memory. Although we did not aim to examine the specific processes of working memory that are affected by stress and/or tDCS but rather to assess 
whether tDCS over the dIPFC could modulate the stress-induced impairment of working memory, targeting the specific cognitive processes involved in the stress-induced working memory deficit and its modulation by dlPFC stimulation is a challenge for future studies. In these studies, it should also be tested how specific the tDCS effect is (i.e., whether tDCS may also be used to modulate stress-induced changes in other cognitive processes, such as memory or decision-making). A further limitation of the present study is related to the relatively low spatial resolution of tDCS. It is possible that cortical areas adjacent to the dIPFC have also received stimulation. In addition, it is unclear how much of the current was shunted through the skull or CSF and thus not reaching the brain at all. Indeed, computational modeling approaches indicate that only a minor portion of the current reaches the brain, especially when the electrodes are placed relatively close to each other (Miranda et al., 2006). Yet, the setup we applied has been used in several previous studies to successfully target dlPFCdependent cognitive functions (Harty et al., 2014; Zwissler et al., 2014; Axelrod et al., 2015; Pope et al., 2015) and to stimulate the dIPFC (Stagg et al., 2013; Weber et al., 2014). Furthermore, it has been shown recently that the brain current density is highest in cortical areas that are directly below the stimulation electrode and decreases with increasing distance from the electrodes (Miranda et al., 2006; Wagner et al., 2014). Finally, the fact that we obtained a behavioral effect of tDCS over the dIPFC may be taken as indication that at least part of the stimulation actually reached the brain. It is thus plausible to assume that the dlPFC was stimulated in the present study. The stimulation of the dlPFC, however, may well have changed activity in other (e.g., medial prefrontal) areas that are intimately linked to the dlPFC and could have played a role in the observed behavioral effects. Although not spatially focused, our findings suggest a potential use of tDCS to improve cognitive performance under stress. Combining brain stimulation with neuroimaging techniques for more precise, individual localization of the electrodes might even enhance these beneficial effects.

In conclusion, our findings show that anodal tDCS over the right dlPFC may prevent working memory impairments induced by acute stress. These findings not only aid our understanding of the functional localization of the impact of stressful experiences on working memory processes but may also have important clinical implications. Anodal tDCS has already been successfully used to improve cognitive functioning in stroke or Alzheimer's patients (Fregni and Pascual-Leone, 2007; Ferrucci et al., 2008; Brunoni et al., 2012). Although the duration and intensity of the stress experienced in clinical conditions are certainly different from the stress experienced in this experiment, our findings suggest that stimulation of prefrontal areas with tDCS could also be a safe, noninvasive tool to alleviate working memory deficits in stress-related psychopathologies, such as depression or anxiety disorders.

\section{References}

Andreano JM, Cahill L (2009) Sex influences on the neurobiology of learning and memory. Learn Mem 16:248-266. CrossRef Medline

Andrews SC, Hoy KE, Enticott PG, Daskalakis ZJ, Fitzgerald PB (2011) Improving working memory: the effect of combining cognitive activity and anodal transcranial direct current stimulation to the left dorsolateral cortex. Brain Stimul 4:84-89. CrossRef Medline

Arnsten AF, Goldman-Rakic PS (1985) Alpha 2-adrenergic mechanisms in prefrontal cortex associated with cognitive decline in aged nonhuman primates. Science 230:1273-1276. CrossRef Medline

Arnsten AF (2009) Stress signalling pathways that impair prefrontal cortex structure and function. Nat Rev Neurosci 10:410-422. CrossRef Medline
Arnsten AF, Li BM (2005) Neurobiology of executive functions: catecholamine influences on prefrontal cortical functions. Biol Psychiatry 57: 1377-1384. CrossRef Medline

Axelrod V, Rees G, Lavidor M, Bar M (2015) Increasing propensity to mindwander with transcranial direct current stimulation. Proc Natl Acad Sci U S A 112:3314-3319. CrossRef Medline

Baddeley A (2003) Working memory: looking back and looking forward. Nat Rev Neurosci 4:829-839. CrossRef Medline

Barbey AK, Koenigs M, Grafman J (2013) Dorsolateral prefrontal contributions to human working memory. Cortex 49:1195-1205. CrossRef Medline

Barsegyan A, Mackenzie SM, Kurose BD, McGaugh JL, Roozendaal B (2010) Glucocorticoids in the prefrontal cortex enhance memory consolidation and impair working memory by a common neural mechanism. Proc Natl Acad Sci U S A 107:16655-16660. CrossRef Medline

Baumgartner T, Knoch D, Hotz P, Eisenegger C, Fehr E (2011) Dorsolateral and ventromedial prefrontal cortex orchestrate normative choice. Nat Neurosci 14:1468-1474. CrossRef Medline

Beck AT, Steer RA, Brown GK (1996) Manual for the beck depression inventory, Vol II. San Antonio, TX: Psychological Corporation.

Boggio PS, Ferrucci R, Rigonatti SP, Covre P, Nitsche M, Pascual-Leone A, Fregni $F$ (2006) Effects of transcranial direct current stimulation on working memory in patients with Parkinson's disease. J Neurol Sci 249: 31-38. CrossRef Medline

Brozoski TJ, Brown RM, Rosvold HE, Goldman PS (1979) Cognitive deficit caused by regional depletion of dopamine in prefrontal cortex of rhesus monkey. Science 205:929-932. CrossRef Medline

Brunoni AR, Nitsche MA, Bolognini N, Bikson M, Wagner T, Merabet L, Edwards DJ, Valero-Cabre A, Rotenberg A, Pascual-Leone A, Ferrucci R, Priori A, Boggio PS, Fregni F (2012) Clinical research with transcranial direct current stimulation (tDCS): challenges and future directions. Brain Stimul 5:175-195. CrossRef Medline

Busch RM, Farrell K, Lisdahl-Medina K, Krikorian R (2005) Corsi blocktapping task performance as a function of path configuration. J Clin Exp Neuropsychol 27:127-134. CrossRef Medline

Cahill L (2006) Why sex matters for neuroscience. Nat Rev Neurosci 7: 477-484. CrossRef Medline

Castaneda AE, Tuulio-Henriksson A, Marttunen M, Suvisaari J, Lönnqvist J (2008) A review on cognitive impairments in depressive and anxiety disorders with a focus on young adults. J Affect Disord 106:1-27. CrossRef Medline

Conrad CD, Galea LA, Kuroda Y, McEwen BS (1996) Chronic stress impairs rat spatial memory on the Y maze, and this effect is blocked by tianeptine treatment. Behav Neurosci 110:1321-1334. CrossRef Medline

de Kloet ER, Joëls M, Holsboer F (2005) Stress and the brain: from adaptation to disease. Nat Rev Neurosci 6:463-475. CrossRef Medline

D’Esposito M, Detre JA, Alsop DC, Shin RK, Atlas S, Grossman M (1995) The neural basis of the central executive system of working memory. Nature 378:279-281. CrossRef Medline

D’Esposito M, Aguirre GK, Zarahn E, Ballard D, Shin RK, Lease J (1998) Functional MRI studies of spatial and nonspatial working memory. Brain Res Cogn Brain Res 7:1-13. CrossRef Medline

Diamond DM, Park CR, Heman KL, Rose GM (1999) Exposing rats to a predator impairs spatial working memory in the radial arm water maze. Hippocampus 9:542-552. CrossRef Medline

Diamond DM, Campbell AM, Park CR, Halonen J, Zoladz PR (2007) The temporal dynamics model of emotional memory processing: a synthesis on the neurobiological basis of stress-induced amnesia, flashbulb and traumatic memories, and the Yerkes-Dodson law. Neural Plast 2007: 1-33. CrossRef Medline

Dickerson SS, Kemeny ME (2004) Acute stressors and cortisol responses: a theoretical integration and synthesis of laboratory research. Psychol Bull 130:355-391. CrossRef Medline

Eid M, Notz P, Steyer R, Schwenkmezger P (1994) Validating scales for the assessment of mood level and variability by latent state-trait analyses. Pers Individ Dif 16:63-76. CrossRef

Elzinga BM, Roelofs K (2005) Cortisol-induced impairments of working memory require acute sympathetic activation. Behav Neurosci 119: 98-103. CrossRef Medline

Ferrucci R, Mameli F, Guidi I, Mrakic-Sposta S, Vergari M, Marceglia S, Cogiamanian F, Barbieri S, Scarpini E, Priori A (2008) Transcranial di- 
rect current stimulation improves recognition memory in Alzheimer disease. Neurology 71:493-498. CrossRef Medline

Fox MD, Snyder AZ, Vincent JL, Corbetta M, Van Essen DC, Raichle ME (2005) The human brain is intrinsically organized into dynamic, anticorrelated functional networks. Proc Natl Acad Sci U S A 102:9673-9678. CrossRef Medline

Fregni F, Pascual-Leone A (2007) Technology insight: noninvasive brain stimulation in neurology-perspectives on the therapeutic potential of rTMS and tDCS. Nat Clin Pract Neurol 3:383-393. CrossRef Medline

Fregni F, Boggio PS, Nitsche M, Bermpohl F, Antal A, Feredoes E, Marcolin MA, Rigonatti SP, Silva MT, Paulus W, Pascual-Leone A (2005) Anodal transcranial direct current stimulation of prefrontal cortex enhances working memory. Exp Brain Res 166:23-30. CrossRef Medline

Fuster JM (1997) Network memory. Trends Neurosci 20:451-459. CrossRef Medline

Fuster JM, Alexander GE (1971) Neuron activity related to short-term memory. Science 173:652-654. CrossRef Medline

Gerlach KD, Spreng RN, Gilmore AW, Schacter DL (2011) Solving future problems: default network and executive activity associated with goaldirected mental simulations. Neuroimage 55:1816-1824. CrossRef Medline

Goldman-Rakic PS (1987) Circuitry of primate prefrontal cortex and regulation of behavior by representational memory. Compr Physiol 373-417.

Goldman-Rakic PS (1994) Working memory dysfunction in schizophrenia. J Neuropsychiatry Clin Neurosci 6:348-357. CrossRef Medline

Guenzel FM, Wolf OT, Schwabe L (2014) Sex differences in stress effects on response and spatial memory formation. Neurobiol Learn Mem 109: 46-55. CrossRef Medline

Haller A, Schwabe L (2014) Sunk costs in the human brain. Neuroimage 97:127-133. CrossRef Medline

Harty S, Robertson IH, Miniussi C, Sheehy OC, Devine CA, McCreery S, O'Connell RG (2014) Transcranial direct current stimulation over right dorsolateral prefrontal cortex enhances error awareness in older age. J Neurosci 34:3646-3652. CrossRef Medline

Harvey PO, Le Bastard G, Pochon JB, Levy R, Allilaire JF, Dubois B, Fossati P (2004) Executive functions and updating of the contents of working memory in unipolar depression. J Psychiatr Res 38:567-576. CrossRef Medline

Honzel N, Justus T, Swick D (2014) Posttraumatic stress disorder is associated with limited executive resources in a working memory task. Cogn Affect Behav Neurosci 14:792-804. CrossRef Medline

Hoy KE, Emonson MR, Arnold SL, Thomson RH, Daskalakis ZJ, Fitzgerald PB (2013) Testing the limits: investigating the effect of tDCS dose on working memory enhancement in healthy controls. Neuropsychologia 51:1777-1784. CrossRef Medline

Jacobson L, Koslowsky M, Lavidor M (2012) tDCS polarity effects in motor and cognitive domains: a meta-analytical review. Exp Brain Res 216:1-10. CrossRef Medline

Jonides J, Smith EE, Koeppe RA, Awh E, Minoshima S, Mintun MA (1993) Spatial working-memory in humans as revealed by PET. Nature 363: 623-625. CrossRef Medline

Kessels RP, van den Berg E, Ruis C, Brands AM (2008) The backward span of the Corsi Block-Tapping Task and its association with the WAIS-III Digit Span. Assessment 15:426-434. CrossRef Medline

Kincses TZ, Antal A, Nitsche MA, Bártfai O, Paulus W (2004) Facilitation of probabilistic classification learning by transcranial direct current stimulation of the prefrontal cortex in the human. Neuropsychologia 42: 113-117. CrossRef Medline

Kirschbaum C, Pirke KM, Hellhammer DH (1993) The 'Trier Social Stress Test': a tool for investigating psychobiological stress responses in a laboratory setting. Neuropsychobiology 28:76-81. CrossRef Medline

Liebetanz D, Nitsche MA, Tergau F, Paulus W (2002) Pharmacological approach to the mechanisms of transcranial DC-stimulation-induced aftereffects of human motor cortex excitability. Brain 125:2238-2247. CrossRef Medline

Lupien SJ, Gillin CJ, Hauger RL (1999) Working memory is more sensitive than declarative memory to the acute effects of corticosteroids: a doseresponse study in humans. Behav Neurosci 113:420-430. CrossRef Medline

Lupien SJ, Maheu F, Tu M, Fiocco A, Schramek TE (2007) The effects of stress and stress hormones on human cognition: implications for the field of brain and cognition. Brain Cogn 65:209-237. CrossRef Medline

Lupien SJ, McEwen BS, Gunnar MR, Heim C (2009) Effects of stress throughout the lifespan on the brain, behaviour and cognition. Nat Rev Neurosci 10:434-445. CrossRef Medline

Marshall L, Mölle M, Siebner HR, Born J (2005) Bifrontal transcranial direct current stimulation slows reaction time in a working memory task. BMC Neurosci 6:23. CrossRef Medline

Martin KP, Wellman CL (2011) NMDA receptor blockade alters stressinduced dendritic remodeling in medial prefrontal cortex. Cereb Cortex 21:2366-2373. CrossRef Medline

McCarthy G, Puce A, Constable RT, Krystal JH, Gore JC, Goldman-Rakic P (1996) Activation of human prefrontal cortex during spatial and nonspatial working memory tasks measured by functional MRI. Cereb Cortex 6:600-611. CrossRef Medline

McEwen BS, Morrison JH (2013) The brain on stress: vulnerability and plasticity of the prefrontal cortex over the life course. Neuron 79:16-29. CrossRef Medline

Miranda PC, Lomarev M, Hallett M (2006) Modeling the current distribution during transcranial direct current stimulation. Clin Neurophysiol 117:1623-1629. CrossRef Medline

Murphy BL, Arnsten AF, Jentsch JD, Roth RH (1996) Dopamine and spatial working memory in rats and monkeys: pharmacological reversal of stressinduced impairment. J Neurosci 16:7768-7775. Medline

Nee DE, Brown JW, Askren MK, Berman MG, Demiralp E, Krawitz A, Jonides J (2013) A meta-analysis of executive components of working memory. Cereb Cortex 23:264-282. CrossRef Medline

Nitsche MA, Paulus W (2000) Excitability changes induced in the human motor cortex by weak transcranial direct current stimulation. J Physiol 527:633-639. CrossRef Medline

Nitsche MA, Fricke K, Henschke U, Schlitterlau A, Liebetanz D, Lang N, Henning S, Tergau F, Paulus W (2003) Pharmacological modulation of cortical excitability shifts induced by transcranial direct current stimulation in humans. J Physiol 533:293-301. CrossRef Medline

Nitsche MA, Cohen LG, Wassermann EM, Priori A, Lang N, Antal A, Paulus W, Hummel F, Boggio PS, Fregni F, Pascual-Leone A (2008) Transcranial direct current stimulation: state of the art 2008. Brain Stimul 1: 206-223. CrossRef Medline

Pessoa L (2008) On the relationship between emotion and cognition. Nat Rev Neurosci 9:148-158. CrossRef Medline

Pope PA, Brenton JW, Miall RC (2015) Task-specific facilitation of cognition by anodal transcranial direct current stimulation of the prefrontal cortex. Cereb Cortex 25:4551-4558. CrossRef Medline

Prager EM, Johnson LR (2009) Stress at the synapse: signal transduction mechanisms of adrenal steroids at neuronal membranes. Sci Signal 2:re5. CrossRef Medline

Qin S, Hermans EJ, van Marle HJ, Luo J, Fernández G (2009) Acute psychological stress reduces working memory-related activity in the dorsolateral prefrontal cortex. Biol Psychiatry 66:25-32. CrossRef Medline

Roozendaal B, McReynolds JR, McGaugh JL (2004) The basolateral amygdala interacts with the medial prefrontal cortex in regulating glucocorticoid effects on working memory impairment. J Neurosci 24: 1385-1392. CrossRef Medline

Roozendaal B, McEwen BS, Chattarji S (2009) Stress, memory and the amygdala. Nat Rev Neurosci 10:423-433. CrossRef Medline

Rottschy C, Langner R, Dogan I, Reetz K, Laird AR, Schulz JB, Fox PT, Eickhoff SB (2012) Modelling neural correlates of working memory: a coordinate-based meta-analysis. Neuroimage 60:830-846. CrossRef Medline

Sandi C, Haller J (2015) Stress and the social brain: behavioural effects and neurobiological mechanisms. Nat Rev Neurosci 16:290-304. CrossRef Medline

Schoofs D, Wolf OT, Smeets T (2009) Cold pressor stress impairs performance on working memory tasks requiring executive functions in healthy young men. Behav Neurosci 123:1066-1075. CrossRef Medline

Schulz P, Schlotz W (1999) The Trier Inventory for the Assessment of Chronic Stress (TICS): scale construction, statistical testing, and validation of the scale work overload. Diagnostica 45:8-19. CrossRef

Schwabe L, Wolf OT (2013) Stress and multiple memory systems: from 'thinking'to 'doing.' Trends Cogn Sci 17:60-68. CrossRef Medline

Schwabe L, Joëls M, Roozendaal B, Wolf OT, Oitzl MS (2012) Stress effects on memory: an update and integration. Neurosci Biobehav Rev 36: 1740-1749. CrossRef Medline

Smeets T, Cornelisse S, Quaedflieg CW, Meyer T, Jelicic M, Merckelbach H (2012) Introducing the Maastricht Acute Stress Test (MAST): a quick and non-invasive 
approach to elicit robust autonomic and glucocorticoid stress responses. Psychoneuroendocrinology 37:1998-2008. CrossRef Medline

Smith EE, Jonides J (1997) Working memory: a view from neuroimaging. Cogn Psychol 33:5-42. CrossRef Medline

Snyder HR (2013) Major depressive disorder is associated with broad impairments on neuropsychological measures of executive function: a metaanalysis and review. Psychol Bull 139:81-132. CrossRef Medline

Sparing R, Dafotakis M, Meister IG, Thirugnanasambandam N, Fink GR (2008) Enhancing language performance with non-invasive brain stimulation: a transcranial direct current stimulation study in healthy humans. Neuropsychologia 46:261-268. CrossRef Medline

Sreenivasan KK, Curtis CE, D'Esposito M (2014) Revisiting the role of persistent neural activity during working memory. Trends Cogn Sci 18: 82-89. CrossRef Medline

Stagg CJ, Lin RL, Mezue M, Segerdahl A, Kong Y, Xie J, Tracey I (2013) Widespread modulation of cerebral perfusion induced during and after transcranial direct current stimulation applied to the left dorsolateral prefrontal cortex. J Neurosci 33:11425-11431. CrossRef Medline

Tabachnick BG, Fidell LS (2005) Using multivariate statistics. Boston: Allyn and Bacon.
Wagner S, Rampersad SM, Aydin Ü, Vorwerk J, Oostendorp TF, Neuling T, Herrmann CS, Stegeman DF, Wolters CH (2014) Investigation of tDCS volume conduction effects in a highly realistic head model. J Neural Eng 11:1-14. CrossRef Medline

Weber MJ, Messing SB, Rao H, Detre JA, Thompson-Schill SL (2014) Prefrontal transcranial direct current stimulation alters activation and connectivity in cortical and subcortical reward systems: a tDCS-fMRI study. Hum Brain Mapp 35:3673-3686. CrossRef Medline

Wechsler D (1997) Wechsler memory scale (WMS-III). San Antonio: Psychological Corporation.

Wechsler D (2008) Wechsler adult intelligence scale, Ed 4 (WAIS-IV). San Antonio: NCS Pearson.

Zaehle T, Sandmann P, Thorne JD, Jäncke L, Herrmann CS (2011) Transcranial direct current stimulation of the prefrontal cortex modulates working memory performance: combined behavioural and electrophysiological evidence. BMC Neurosci 12:1-11. CrossRef Medline

Zwissler B, Sperber C, Aigeldinger S, Schindler S, Kissler J, Plewnia C (2014) Shaping memory accuracy by left prefrontal transcranial direct current stimulation. J Neurosci 34:4022-4026. CrossRef Medline 